\title{
Environmental Restoration by New Technology for Prevention of Soil Erosion and Revegetation on Bare Slopes
}

\author{
Takuya Marumoto and Nobuyuki Kohno \\ Takino Filter Inc., Kudamatsu 744-0061, Japan
}

\begin{abstract}
In order to prevent soil erosion and promote reforestation on devastated bare slopes, the ecological new technology using MS (Mulching Sheet: nonwoven fabric sheet with two to four layer structures) and GB (Green Bag: made of MS containing plant seeds, fertilizers, vegetation base materials, and mycorrhizal fungi) has been applied to bare slopes not only in Japan but also in Korea, Taiwan, China, Indonesia, Vietnam etc. since 1990. From the results of them, the following conclusions were obtained: (1) This technology was significantly effective in preventing soil erosion and promoting the early revegetation on bare slopes; (2) It was suggested that the initial reforestation period could be accelerated for about 50 years by this technology in the Temperate Zone by many field data obtained.
\end{abstract}

Key words: Ecological reforestation, MS (Mulching Sheet), GB (Green Bag), mycorrhizal fungi.

\section{Introduction}

In the twentieth century, much environmental destruction was caused by natural disasters and human activities (Fig. 1). As a result of the environmental destruction, some serious problems, for instance, increase of $\mathrm{CO}_{2}$ concentration and destruction of ozone layer were observed. And vicious circle of environmental destruction is circulating now (Fig. 2). Then, serious pollutions of air, water and soil occurred in the twentieth century.

Water resource is the most important matter for human beings. Fresh water is about $2.53 \%$ of total amount of water $\left(138.6 \times 10^{8}\right.$ million ton $)$ on the earth. And, available fresh water for human is about $0.34 \%$ of fresh water (quite small amount of available fresh water). Further, about $40 \%$ of river water is polluted now.

In order to maintain water resource and reduce $\mathrm{CO}_{2}$ concentration in atmosphere, revegetation and reforestation under preventing soil erosion are the most

Corresponding author: Takuya Marumoto, Ph.D., main research field: soil biochemistry. important matters. A MS (Mulching Sheet: non-woven fabric sheet with four layers' structure at most, Fig. 3) and a GB (green bag: 3-5 kg made of MS containing plant seeds, fertilizers, vegetation base materials and mycorrhizal fungi, Fig. 4) were developed by Marumoto, T. et al. [1, 2] and were applied to devastated bare slopes in many countries (1995-2016). It was found that this ecological reforestation technology using MS, GB and mycorrhizal fungi [3] was significantly effective and useful to prevent soil erosion and to promote the early revegetation on bare slopes.

In this paper, some construction cases of environmental restoration by the use of new technology with which the multi-function of MS (Fig. 5) and GB including mycorrhizal fungi (Figs. 4 and 6) were utilized for the prevention of soil erosion and reforestation on bare slopes are introduced (Figs. 7-12).

\section{Materials}

\section{$2.1 M S$}

The basic structure of MS (commercial name is "Takino-Filter") is shown in Fig. 3. MS is composed 


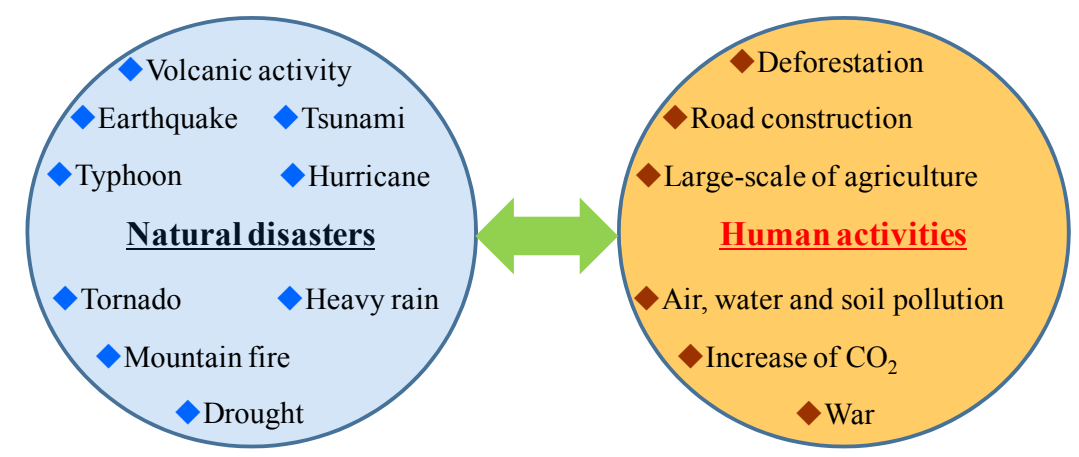

Fig. 1 Causes of environmental destruction.

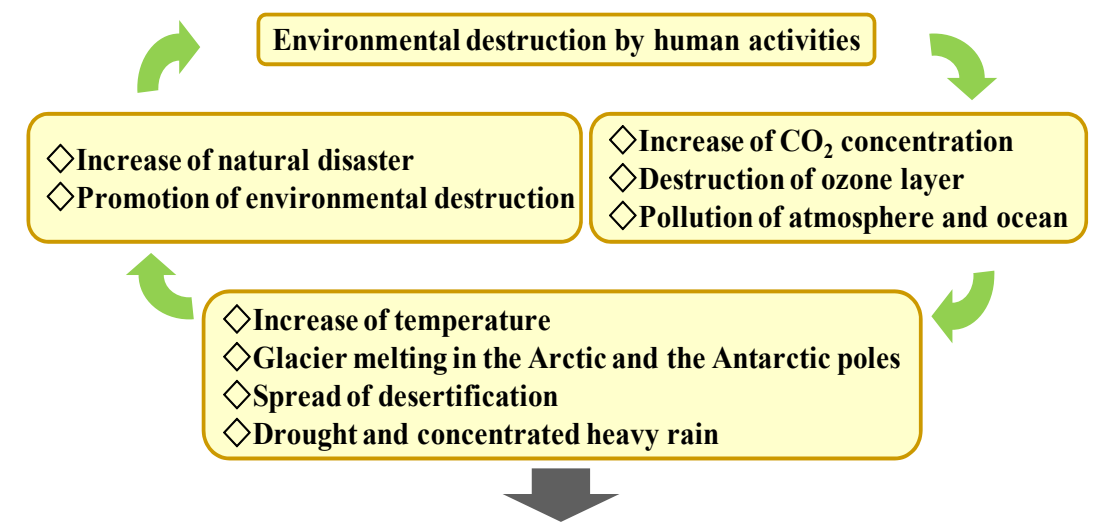

Serious pollutions of Air, Water and Soil

Fig. 2 Vicious circle of the environmental destruction.

of four layers at most: the first layer is polyethylene protection net; the second layer is polyester non-woven fabric (Web); the third layer is composed of plant seeds, fertilizers and vegetation base materials and the fourth layer is cotton base cloth. When the main purpose is prevention of soil erosion, MS of two layers composed of the first and the second layers is used mainly. From the experimental results during 5 years (1987-1992), it was found that MS had many interesting functions as Fig. 5 [4]:

(1) Prevention of surface soil erosion under 100 $\mathrm{mm}$ rainfall per hour (fix the surface soil);

(2) Maintenance of the moisture under the sheet (decrease of drought damage);

(3) Maintenance of the temperature under the sheet in winter (decrease of frozen damage);

(4) Well drainage in the sheet;

(5) Softening of the rain drop impact;

(6) Improvement of root zone in the soil (increase of microorganisms);

(7) Acceleration of soil formation.

\section{$2.2 B G$}

The basic structure of BG is shown in Fig. 4. GB was initially developed to promote reforestation by broadcasting from helicopter in large area of devastated site covered with the pyroclastic flow deposit in Mt. Fugendake, Shimabara-shi, Nagasaki, Japan in 1995. GB is composed of three components: the first component is protection net made of polyethylene, biodegradable polyethylene or palm etc.; the second component is non-woven fabric sheet made of polyester etc. and the third component is composed of plant seeds, fertilizers, vegetation base materials and mycorrhizal fungi. After then, GB has been used in many devastated lands such as pyroclastic flow deposit except Mt. Fugendake, mine site and highly acidic soil site etc.. 


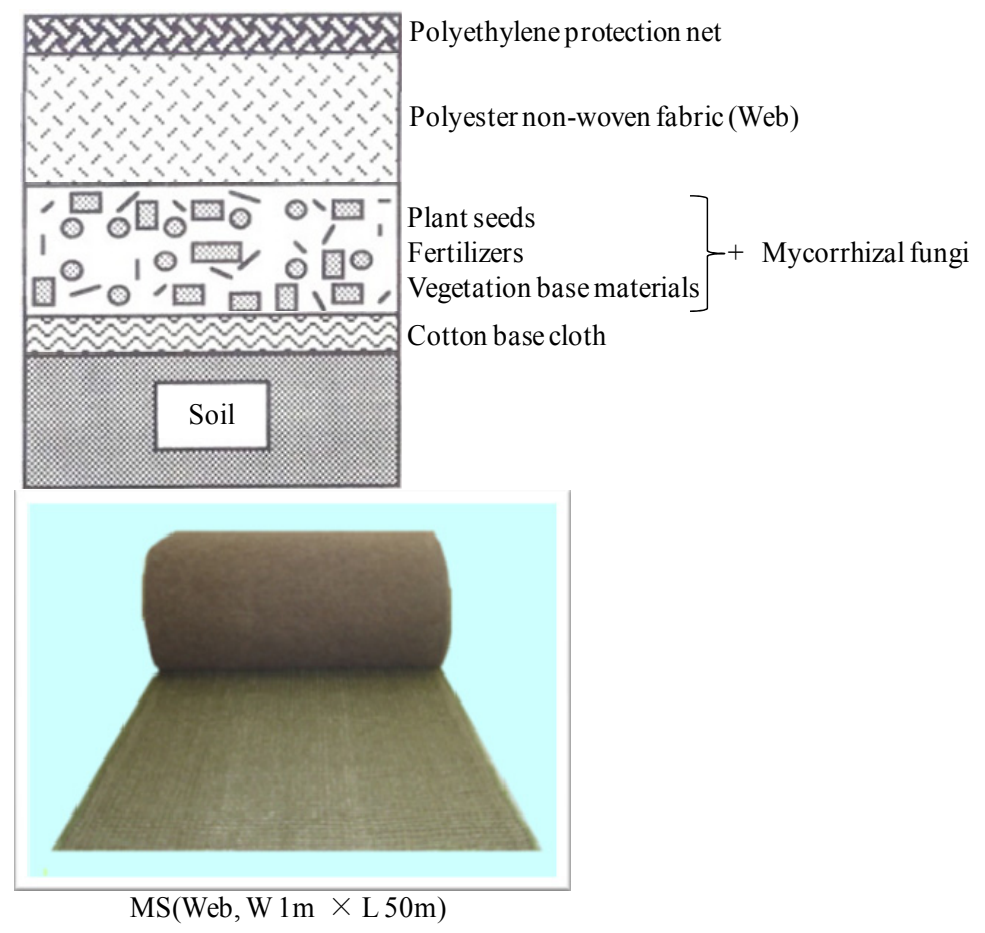

Fig. 3 Basic structure of MS.
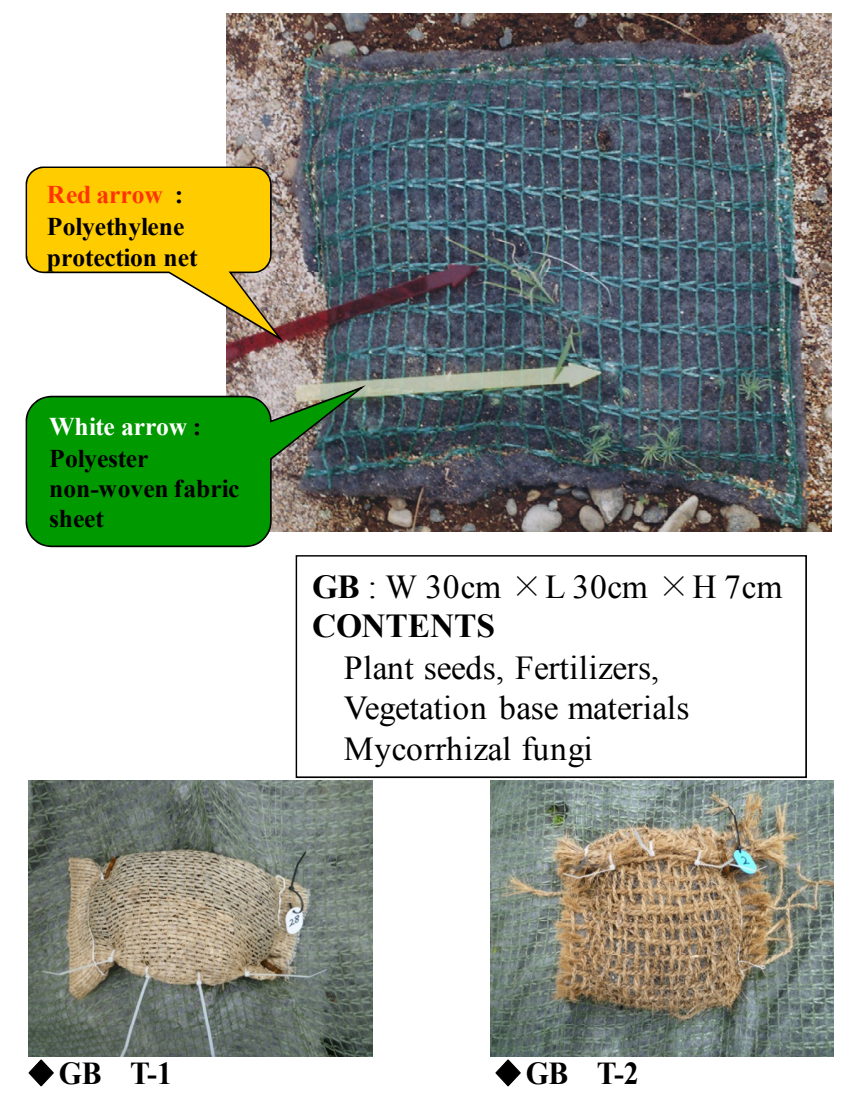

( Biodegradable polyethylene net )

$\mathrm{L} 300 \mathrm{~mm} \times \mathrm{W} 430 \mathrm{~mm}$

( Palm net )

$\mathrm{L} 300 \mathrm{~mm} \times \mathrm{W} 430 \mathrm{~mm}$

Fig. 4 GB broadcasted by helicopter in devastated area of Mt. Fugendake, Shimabara-shi, Nagasaki, Japan, 1995. 


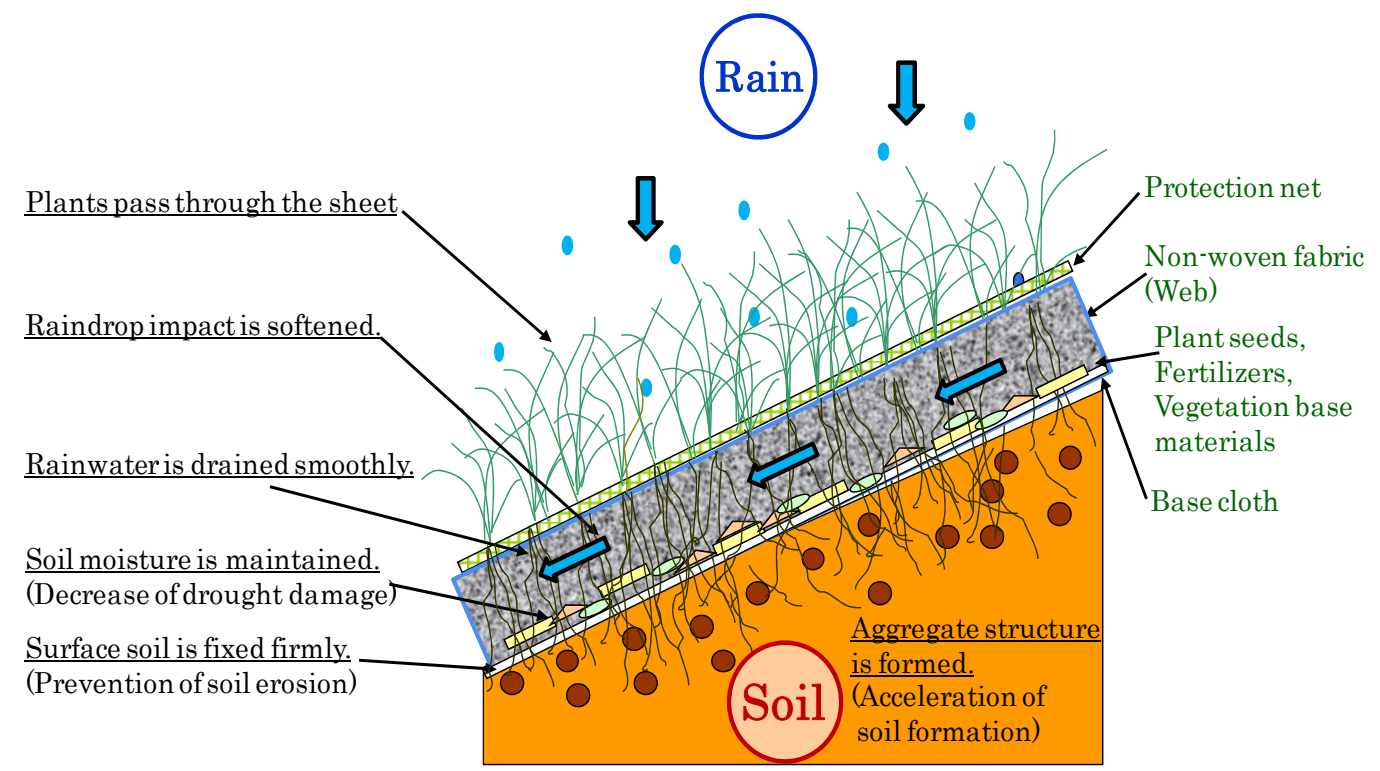

Fig. 5 Multi-function of MS for prevention of soil erosion and revegetation on bare slope.

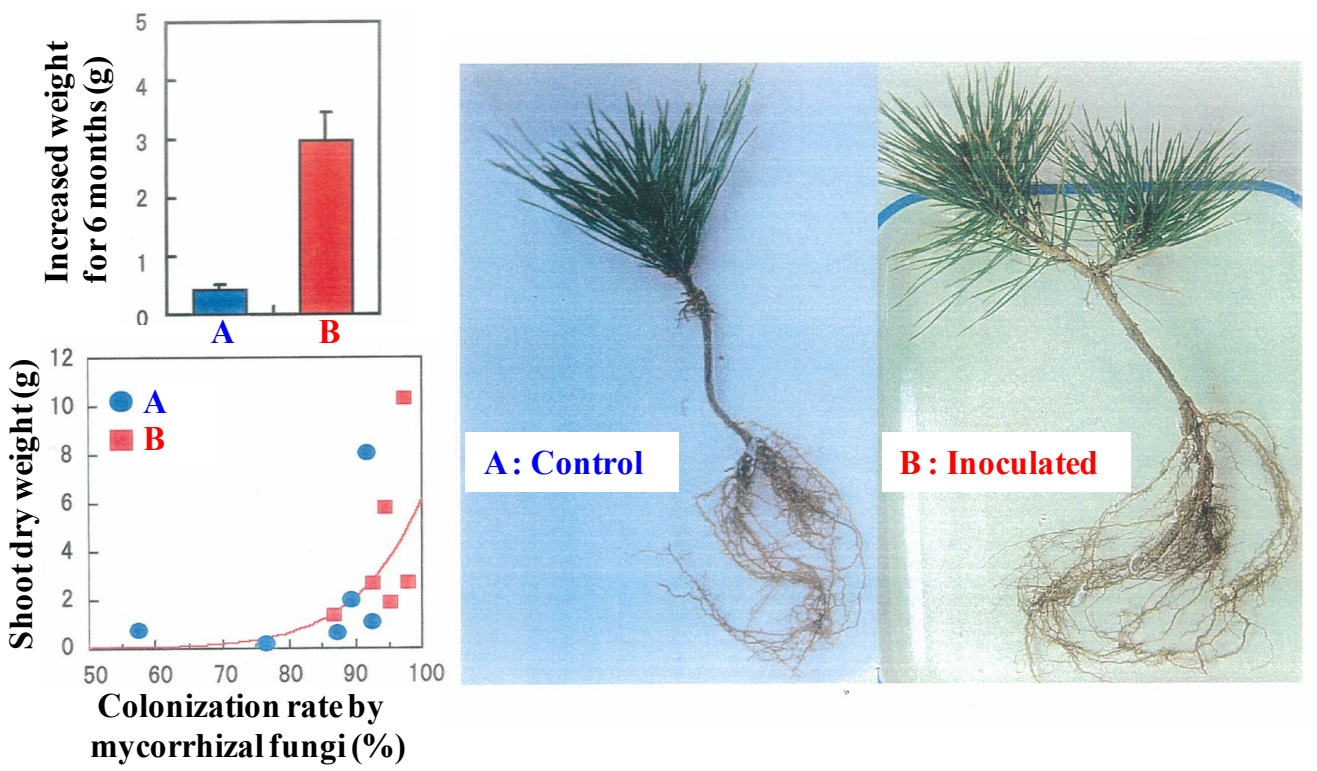

Fig. 6 Effect of symbiosis with ectomycorrhizal fungi to young pine seedling for 6 months, 2001.

\subsection{Mycorrhizal Fungi}

Mycorrhizal fungi are one of the most popular symbiotic microorganisms in the world. Effect of ectomycorrhizal fungi (Suillus sp.) on the growth of young pine seedling and their colonization for 6 months (2001) are shown in Fig. 6. Plant growth and revegetation of young pine seedling were accelerated for 6 months by mycorrhizal fungal inoculation. The MS and GB containing mycorrhizal fungi were usually used for the recovery of bare slopes in Japan.

\section{Results and Discussions}

3.1 Reforestation of Bare Slope at Naganoyama Mountain Site of Kanokami, Shunan-shi, Yamaguchi, Japan (1990-2000, Fig. 7)

MS was applied on bare slope of mountain site (1,000 $\mathrm{m}$ height, frozen area in winter time) of Kanokami, Shunan-shi, Yamaguchi on Dec., 1990. Revegetation progressed yearly and recovered to almost the same as former situation of mountain site after 10 years. And the number of soil microbes such as 
bacteria and fungi under MS was higher than the bare site.

\subsection{Revegetation of Bare Slope of Shirasu (White} Volcanic Ash Soil) at Tokiya District, Miyazaki-shi, Miyazaki, Japan (1991, Fig. 8)

Shirasu (white volcanic ash soil) is located in south area of Kyushu Island (Miyazaki and Kagoshima). The prevention of soil erosion of "Shirasu" is usually very difficult under strong rainfall in rainy season in southern Japan. As shown in Fig. 8, soil erosion was completely prevented and revegetation also succeeded 2 months later after construction of MS on bare slopes at Tokiya district, Miyazaki, Japan in June-Aug., 1991. And, the amount of soil microbial biomass $\mathrm{C}$ increased in MS plots than in bare (control) plots after 1 and 3 years.

\subsection{Reforestation of Volcanic Barren Area of Mt.} Fugendake, Nagasaki, Japan (1995-1996, Figs. 9 and 10)

Situation of Mt. Fugendake area after volcanic explosion at Shimabara peninsula is shown in Fig. 9.
South side of mountain was burned completely by pyroclastic flow (about 1,300 degrees Celsius).

Construction of reforestation was started on burned area in 1995. GB was broadcasted on the barren area by helicopter (Fig. 10). Four years later after broadcasting of GB on bare field, the land had been completely covered with bush and young trees. A large number of trees grew higher than $5 \mathrm{~m}$ tall 10 years later [5]. And the inoculated arbuscular mycorrhizal fungus, Gigaspora margarita MAFF520054 strain, was detected by the specific molecular sequence method four years later after construction and it was suggested that the fungus had contributed to the establishment and the growth of introduced plant species and the promotion of reforestation [6-8].

3.4 Reforestation of Rock Slope on Dam Sites, at Nukui Dam, Kake, Akiohta-cho, Hiroshima by MS and GB (1999-2015, Figs. 11 and 12)

Nukui Dam with arch style was constructed at Kake, Akiohta-cho, Hiroshima and the construction for reforestation of rock slope on dam sites was executed
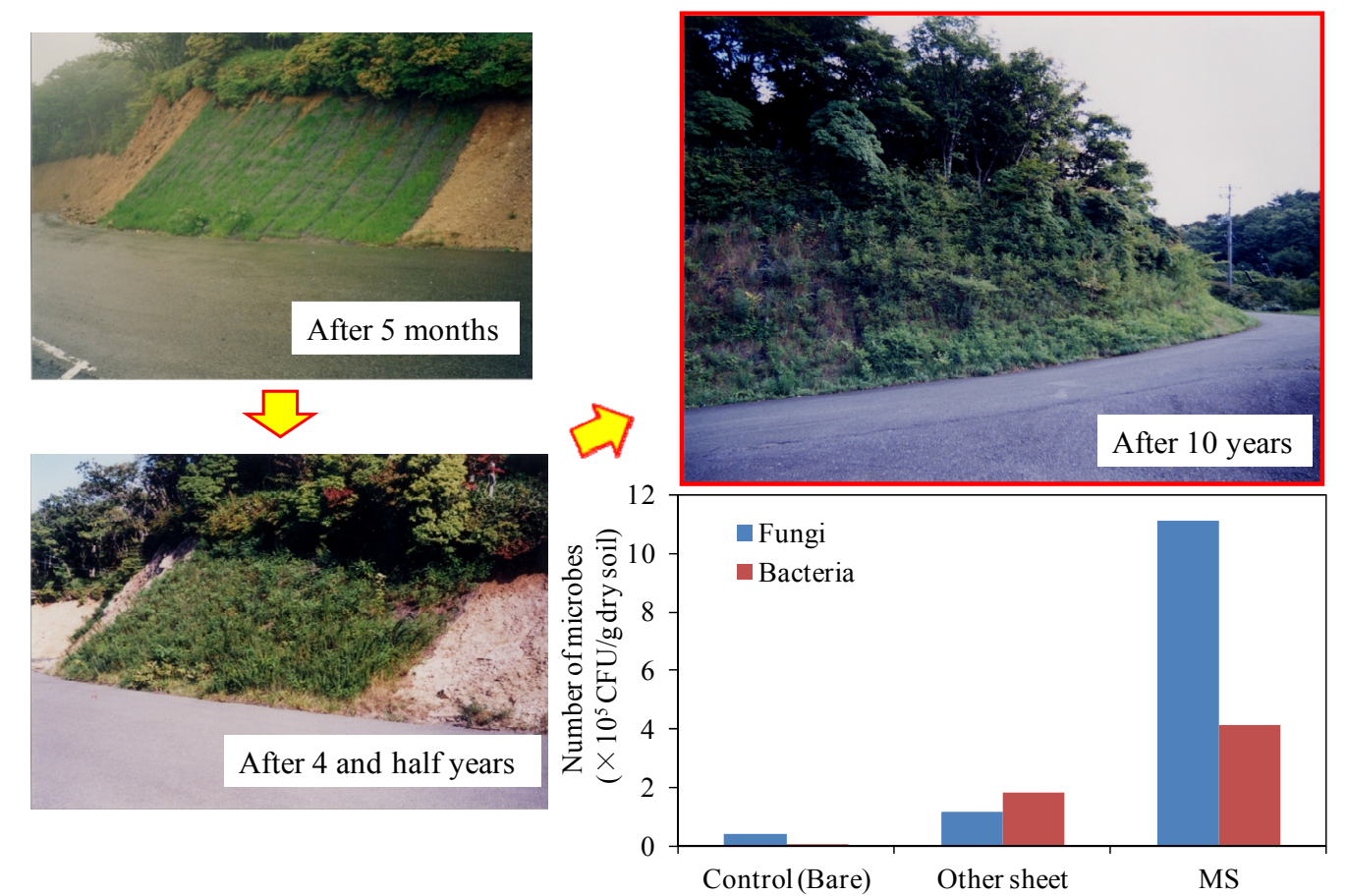

Fig. 7 Reforestation of bare slope of Naganoyama mountain site of Kanokami, Shunan-shi, Yamaguchi, Japan in December, 1990. 


\section{Environmental Restoration by New Technology for Prevention of Soil Erosion and Revegetation on Bare Slopes}

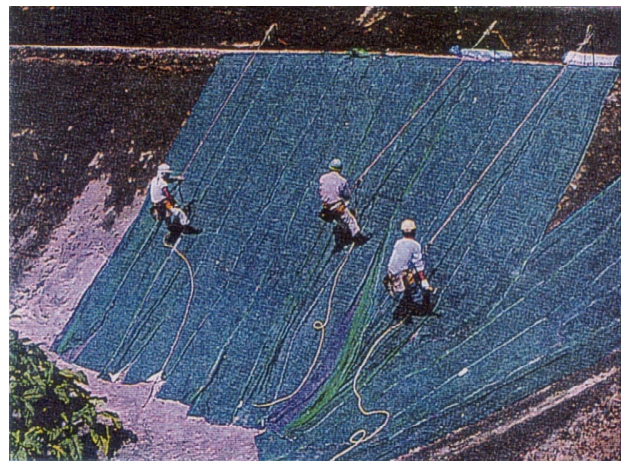

Under construction

Fig. 8 Revegetation of bare slope of Shirasu (white volcanic ash soil) at Tokiya district, Miyazaki-shi, Miyazaki, Japan, 1991.

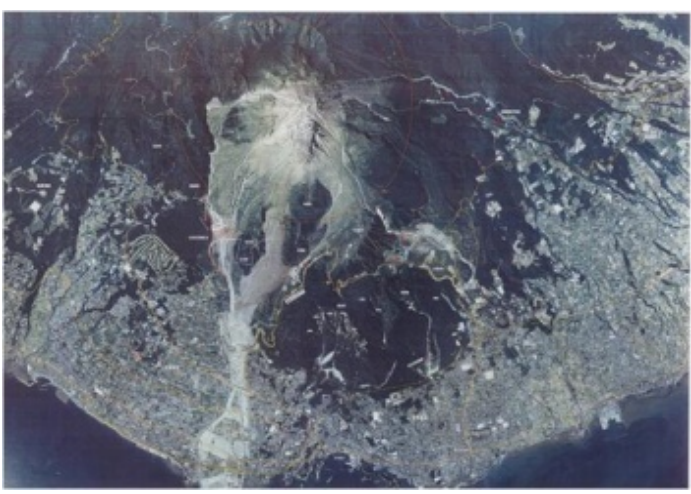

(a) Pyroclastics flow from Mt. Fugendake.

Fig. 9 Situation after explosion of Mt. Fugendake, Nagasaki, 1994.

in 1999. The situation of reforestation on both dam sites after 9 and 15 years were shown in Figs. 11 and 12. Rock slope on dam sites had completely recovered by MS and GB using these ecological technologies. And the survival of inoculated AM (Arbuscular Mycorrhizal) fungus was also confirmed in this site and it was suggested that the fungus contributed to the success of reforestation [8].

\section{Conclusion}

In order to prevent soil erosion and promote
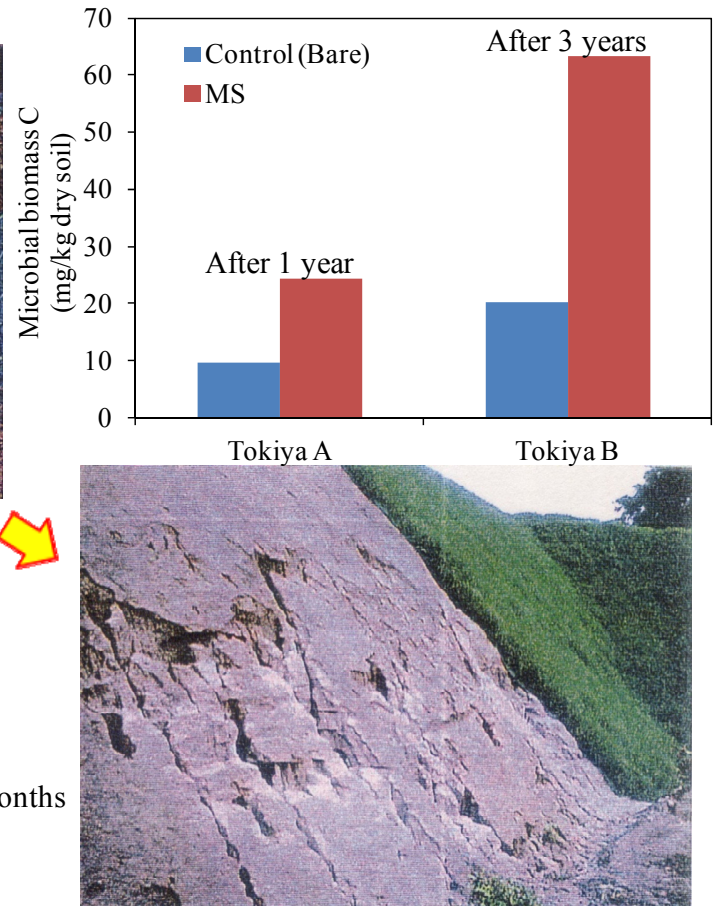

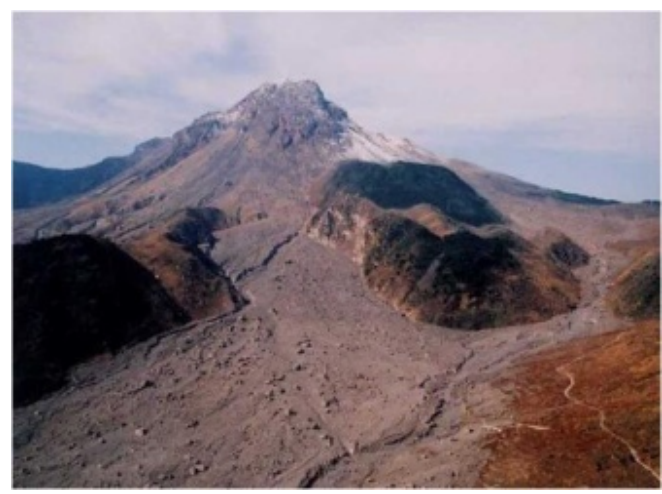

(b) Mountain site burned to sea side by pyroclastic flow.
65

After 2 months

reforestation on devastated bare slopes, the ecological new technology using MS (nonwoven fabric sheet with four layer structure) and GB (made of MS containing plant seeds, fertilizers, vegetation base materials, and mycorrhizal fungi) has been applied to bare slopes not only in Japan, but also in Korea, Taiwan, China, Indonesia, Vietnam etc. since 1990.

(1) This technology was significantly effective in preventing soil erosion and promoting the early revegetation on bare slopes. 

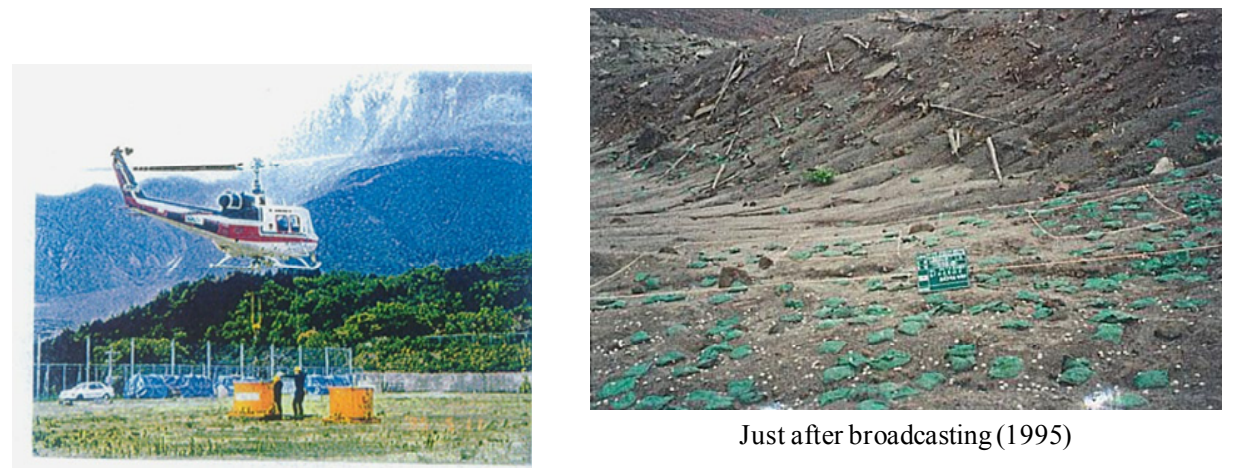

Just after broadcasting (1995)

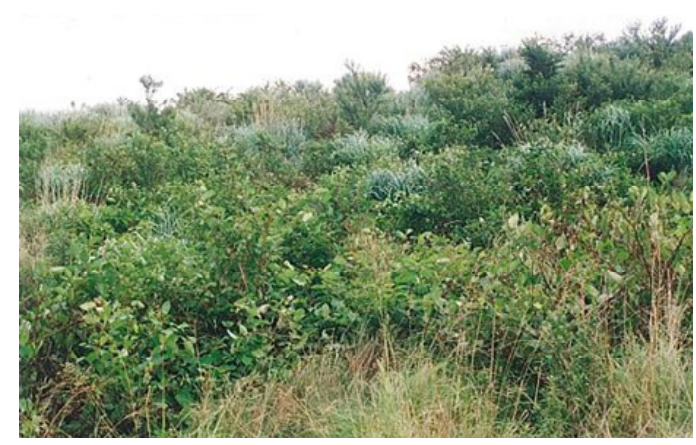

After 4 years (1999)

Fig. 10 Reforestation of volcanic barren area at Mt. Fugendake by broadcasting of Green-bags using helicopter (1995-1999) $[9,10]$.

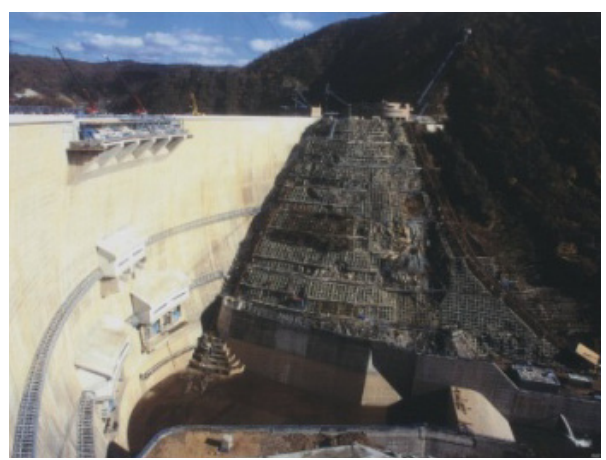

(a) Before construction of rock slope.

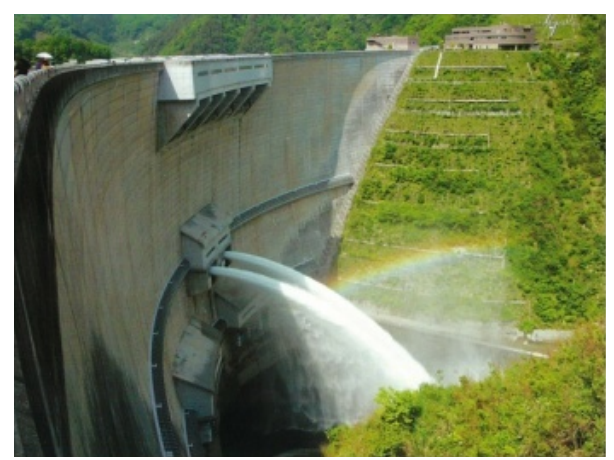

(b) 9 years later after construction, 1999.

Fig. 11 Reforestation of rock slope on dam sites, Nukui Dam, Kake, Akiohta-cho, Hiroshima by MS and GB, 1999-2008.
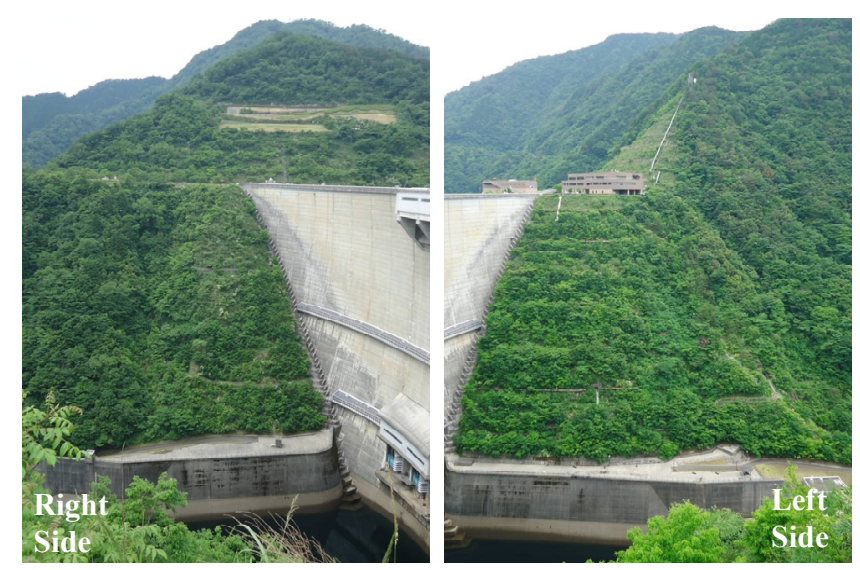

Fig. 12 Nukui Dam sites after 15 years of reforestation, 2015. 


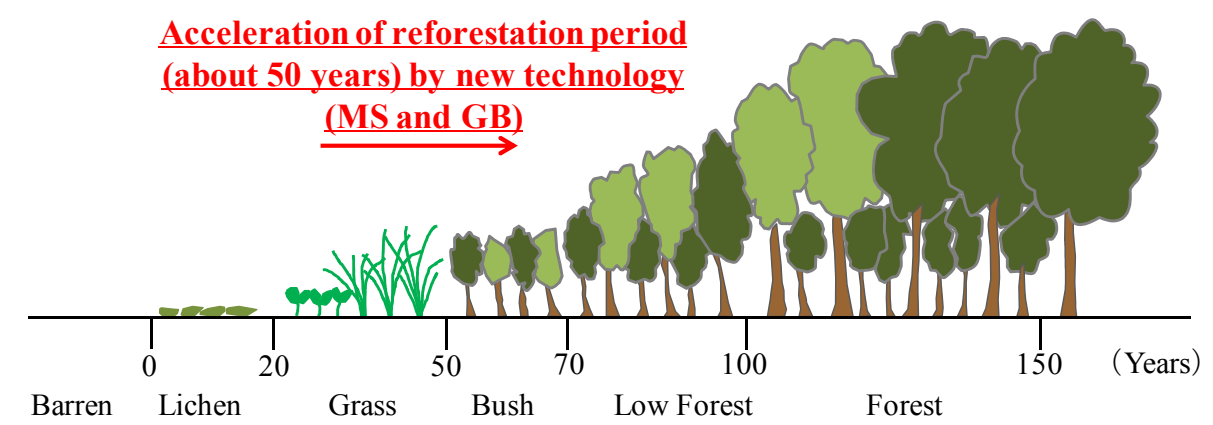

Fig. 13 Vegetation succession from barren to forest in the Temperate Zone [5].

(2) It was suggested that the initial reforestation period could be accelerated for about 50 years by this technology in the Temperate Zone by many field data obtained (Fig. 13).

Finally, authors strongly hope that this technology is expanded and utilized on bare slopes and the authors would like to contribute to the environmental restoration in the world.

\section{References}

[1] Marumoto, T., Fujiwara, T., Tsunemura, T., Tsunemori, I., Yamamoto, K., and Okinaga, K. 1990. "Based on the Ecological Viewpoint-Development of the Material for Prevention of Soil Erosion and Revegetation." Proceedings of the Conference about Natural Disasters and Global Environmental Problems: 16-24.

[2] Marumoto, T., Okabe, H., Ezaki, T., Nishiyama, M., and Yamamoto, K. 1996. "Application of Symbiotic Microorganisms to Soil Conservation and Reforestation." In Proceedings of International Symposium, Bio-Japan, 242-50.

[3] Okabe, H., Marumoto, T., Esaki, T., and Yamamoto, K. 1997. "Effectiveness of Mycorrhizal Association in Revegetation." Journal of Agricultural Meteorology 52 (5): 609-12.
[4] Marumoto, T., Hayakawa, S., Esaki, T., and Okabe, H. 1997. "Function of a Mulching Sheet for Reforestation and the Prevention of Soil Erosion." Journal of Agricultural Meteorology 52 (5): 613-6.

[5] Yamasaki, K., and Takahashi, Y. 2015. "Experimental Works on Rapid Reforestation by Aerial Seeding in the Devastated Slope of Unzen Volcano." Journal of the Japan Society of Erosion Control Engineering 68: 78-82.

[6] Yokoyama, K., Tateishi, T., Marumoto, T., and Saito, M. 2002. "A Molecular Marker Diagnostic of a Specific Isolate of an Arbuscular Mycorrhizal Fungus, Gigaspora Margarita." FEMS Microbiology Letters 212 (2): 171-5.

[7] Yokoyama, K., Tateishi, T., Kohno, N., Saito, M., and Marumoto, T. 2002. "Isolate-specific Detection of an Arbuscular Mycorrhizal Fungus, Gigaspora Margarita Inoculated in Soil.” Soil Microorganisms 56 (2): 103-8.

[8] Marumoto, T., and Kohno, N. 2005. "Environmental Conservation for Devastated Slopes Using Ecological Reforestation Technology." Journal of Agricultural Meteorology 60 (5): 491-3.

[9] Marumoto, T., and Kohno, N. 2001. "Revegetation of Volcanic Devastated Land Using the Symbiosis with Mycorrhizal Fungi." Journal of the Japanese Society of Revegetation Technology 26 (4): 258-64.

[10] Saito, M., and Marumoto, T. 2002. "Inoculation with Arbuscular Mycorrhizal Fungi: The Status Quo in Japan and the Future Prospects." Plant and Soil 244: 273-9. 